\title{
A Cold Model Study on the Effect of Gas Injection upon the Melting Rate of a Solid Sphere in a Liquid Bath*
}

\author{
By Shigeji TANIGUCHI,** Munekazu OHMI,** Shinji ISHIURA ${ }^{* * *}$ \\ and Satoshi YAMAUCHI****
}

\begin{abstract}
Synopsis
A study was carried out on the effect of gas injection upon the melting rate of an ice sphere in a water bath.

Heat transfer coefficient was obtained from the experiment in which the melting rate of an ice sphere was measured. The ice sphere was placed in the upward flow generated by the gas injection through an orifice at the bath bottom.

The heat transfer coefficient increased with an increase in the gas flow rate, while it was not influenced much by the orifice diameter and vessel shape.

An attempt was also made to estimate the heat transfer coefficient and it was found that Whitaker's heat transfer equation was applicable when the average velocity of the upward flow was known. A tracer method and a method based on the energy balance consideration were employed for obtaining the velocity. The latter method involved mainly calculation.
\end{abstract}

\section{Introduction}

Gas injection into a liquid bath has long been used for various engineering purposes, since it is very effective to increase the overall reaction rate or to shorten the mixing time. These advantages are based on the fact that large interfacial area between gas and liquid, and strong stirring of the bath can be obtained by the gas injection.

The application of the gas injection technique to steelmaking processes is becoming increasingly popular in recent years and outstanding performances have been reported, for instance, in the $\mathrm{Q}-\mathrm{BOP}^{1)}$ and $\mathrm{AOD}^{2)}$ operations.

The advantage of the gas injection can also be seen in the enhanced heat transfer process by the bath agitation resulted from the gas injection. Consequently, the gas injection may prove itself very effective for melting the scrap or metallized iron agglomerates in a steel bath.

However, only few studies ${ }^{3)}$ seem to have been carried out on this respect. The short melting time is prerequisite for a high efficiency operation.

The present study deals with the effect of the gas injection on the melting rate of a sphere placed in a liquid bath. An ice sphere-water system is used here as a cold model. In this system the melting rate is controlled by the heat transferred from the surrounding water.

The effect of the gas injection is evaluated in terms of heat transfer coefficient obtained from the experiment. Influences of orifice diameter, vessel shape and gas flow rate will be discussed. Further, a comparison of the heat transfer coefficient obtained by the experiment and that calculated by using an equation in the literature is also presented.

The present cold model study will be followed by a hot model study in a separate paper.

\section{Experimental}

The gas injection into a water bath through an upward orifice at the bath bottom establishes a circulating flow regime in the bath with an upward flow above the orifice. The major part of the present experimental work consisted of the measurement of the melting rate of an ice sphere in the upward flow with a photographic technique.

The experimental assembly used for the measurement of the melting rate and an ice sphere melting in the bath are shown in Fig. 1 and Photo. 1, respectively. The electric bulb in Fig. 1 was used for obtaining good illumination for photography.

The ice sphere of about $3.6 \mathrm{~cm}$ diameter was made by solidifying water in a spherical plastic mold which was kept in a refrigerator. The sphere was fixed on the sheathed end of a brass tube of $0.2 \mathrm{~cm}$ diameter for handling and holding. The sheath, which is seen in Photo. 1, was made of wood reaching the center of the sphere and used for preventing the heat conduction through the brass rod during the experi-
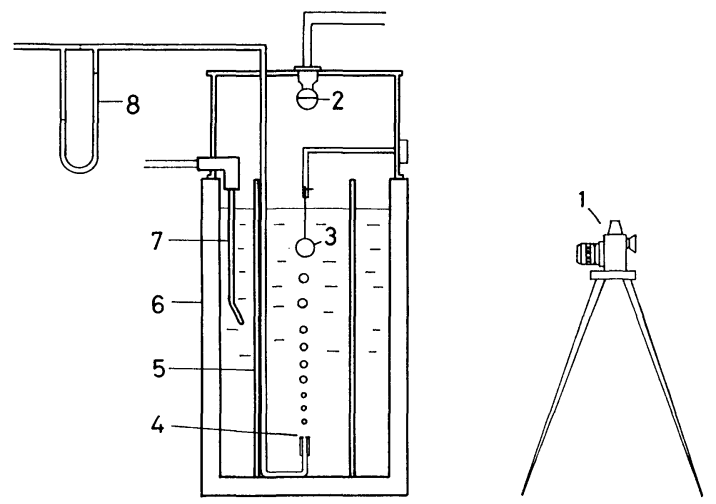
1. camera
5. test vessel
2. electric bulb
3. specimen sphere
4. orifice
outer vessel
7. heater
8. Hlow meter

Fig. 1. Experimental assembly used for measuring the melting rate of an ice sphere.

\footnotetext{
* Partly presented to the 102nd ISIJ Meeting, November 1981, S865, at Kyoto-fu Chusho Kigyo Kaikan in Kyoto. Manuscript received May 24, 1982. (C) 1983 ISIJ

** Department of Metallurgical Engineering, Faculty of Engineering, Osaka University, Yamadaoka, Suita 565.

*** Formerly Graduate School, Osaka University. Now at Nakayama Steel Works, Ltd., Funamachi, Taisho-ku, Osaka 551.

**** Formerly Graduate School, Osaka University. Now at Osaka Titanium Co., Ltd., Amagasaki 660.
} 


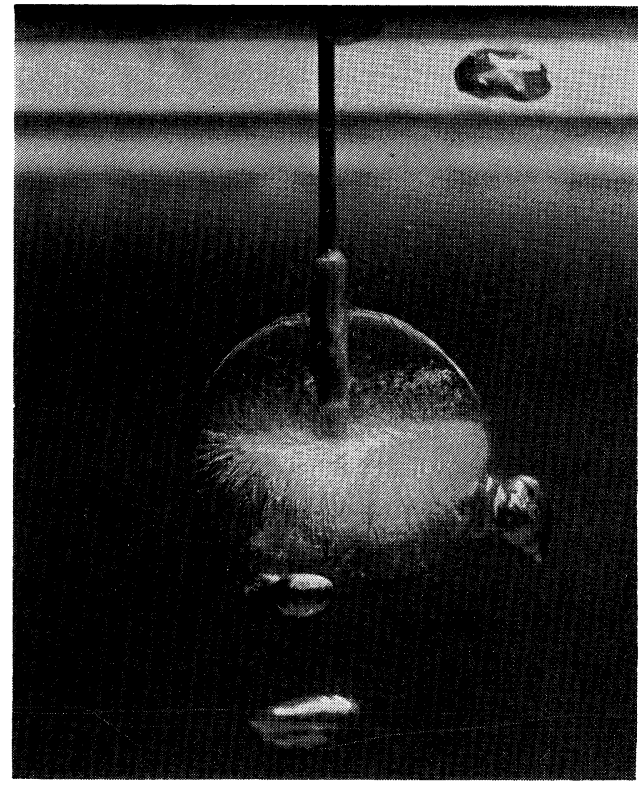

Photo. 1. Ice sphere melting in the water bath.

ment. The error caused by neglecting the volume of the sheath was less than $0.4 \%$ for a short time.

A preliminary test with a thermometer revealed that the temperature in the sphere throughout was $0{ }^{\circ} \mathrm{C}$ during the measurement.

High purity nitrogen gas of a commercial source was injected into the water bath through a flow meter, a brass tube of $0.6 \mathrm{~cm}$ inner diameter and an orifice. The gas flow rate ranged from 0.64 to $5.3 \mathrm{~N} l / \mathrm{min}$. The orifice was made of an acrylic plate of $0.5 \mathrm{~cm}$ thickness with a cylindrical hole of $0.1,0.2$, or $0.43 \mathrm{~cm}$ diameter.

Three kinds of vessels were used, sizes of which are shown below;

(a) $30 \mathrm{~cm} \times 14 \mathrm{~cm} \times 43 \mathrm{~cm}$ (height),

(b) $30 \mathrm{~cm} \times 4.5 \mathrm{~cm} \times 36 \mathrm{~cm}$ (height), and

(c) $15 \mathrm{~cm}$ (diameter) $\times 36 \mathrm{~cm}$ (height).

Vessel (a) is a representative of that having a rectangular horizontal cross section, while vessel (b) has a narrow space and results in a nearly two dimensional flow regime in the bath. On the other hand, vessel (c) has a circular horizontal cross section. The shape of ordinary industrial bath may belong to one of these three. All the vessels were made of transparent acrylic resin, which thus allows the observation of the sphere and the flow regime in the bath.

After a stable flow regime was established in the bath a specimen sphere was immersed in the bath and held at $6 \mathrm{~cm}$ below the bath surface and $27 \mathrm{~cm}$ above the orifice with the aid of a cramp. Then, the specimen was photographed at $10 \mathrm{~s}$ intervals through a side wall.

Since the specimen shape deviated from a sphere slightly as the melting time elapsed, the average diameter was obtained from those measured on a photograph in four directions with $45 \mathrm{deg}$ apart. Measurements were carried out more than three times for a set of conditions.

In order to examine the applicability of a few reported heat transfer equations to the ice sphere- water system, a preliminary experiment was carried out in which the melting rate of an ice sphere in a single phase water flow was measured. For this purpose a large circulating water channel, which is usually used for studies of naval architecture, was employed. The test section of a uniform velocity distribution behind a honeycomb was $1.6 \mathrm{~m}$ wide, $3.3 \mathrm{~m}$ long and $1.0 \mathrm{~m}$ deep. The flow direction was horizontal and the water temperature was $7.5^{\circ} \mathrm{C}$.

The specimen sphere was immersed $10 \mathrm{~cm}$ below the surface at the center of the test section and was photographed through a side window. The flow velocity ranged from 17.6 to $41.3 \mathrm{~cm} / \mathrm{s}$ and its fluctuation was less than $10 \%$ of a specified value. This experiment will be hereafter referred to as the preliminary experiment.

\section{Estimation of Heat Transfer Coefficient}

If the average velocity of the upward flow in the bath is known, it is possible to estimate the heat transfer coefficient by using the heat transfer equation presented by Whitaker, ${ }^{4)}$ the applicability of which will be discussed in the next section.

Two methods were used for obtaining the average velocity of the upward flow; (1) a tracer method and (2) a method based on calculation from energy balance consideration in which experimental values of $r$, radius of the upward flow, are used.

In method (1) wood saw powder of about $0.1 \mathrm{~cm}$ size was used as a tracer and the average velocity was obtained from the length of many traces recorded on photographs. An example of the flow pattern revealed by the tracer is shown in Photo. 2 in which the upward flow and circulating flow are recognized. The upward flow was found to be approximately cylindrical, but it changed to slightly conical as the gas flow rate increased.

In method (2) it is assumed that the work brought into the bath by the gas injection is almost equal to the work consumed for maintaining the upward flow. Mori and $\mathrm{Sano}^{5)}$ recently presented a comprehensive review on the work done by the gas injected into a liquid bath. On the basis of their discussion, the work done by the buoyancy force and by the kinetic energy of the gas was taken into account in the present study.

The work done by the buoyancy force per unit time $W_{\mathrm{b}}$ is

$$
W_{\mathrm{b}}=\frac{V_{\mathrm{g}} R T}{22.4 \times 60} \ln \left[1+\frac{\rho_{1} g H}{P_{\mathrm{a}}}\right]
$$

The work brought into the bath by the kinetic energy of the gas per unit time at the orifice $W_{\mathrm{g}}$ is

$$
W_{\mathrm{g}}=\frac{1}{2}\left(\rho_{\mathrm{g}} u S\right) u^{2}
$$

This is converted into the following form:

$$
W_{\mathrm{g}}=0.1033 M V_{\mathrm{g}}^{3}\left(\frac{\mathcal{T}}{273}\right)^{3} / S^{2}
$$

However, a large part of $W_{\mathrm{g}}$ was reported ${ }^{3)}$ to be 


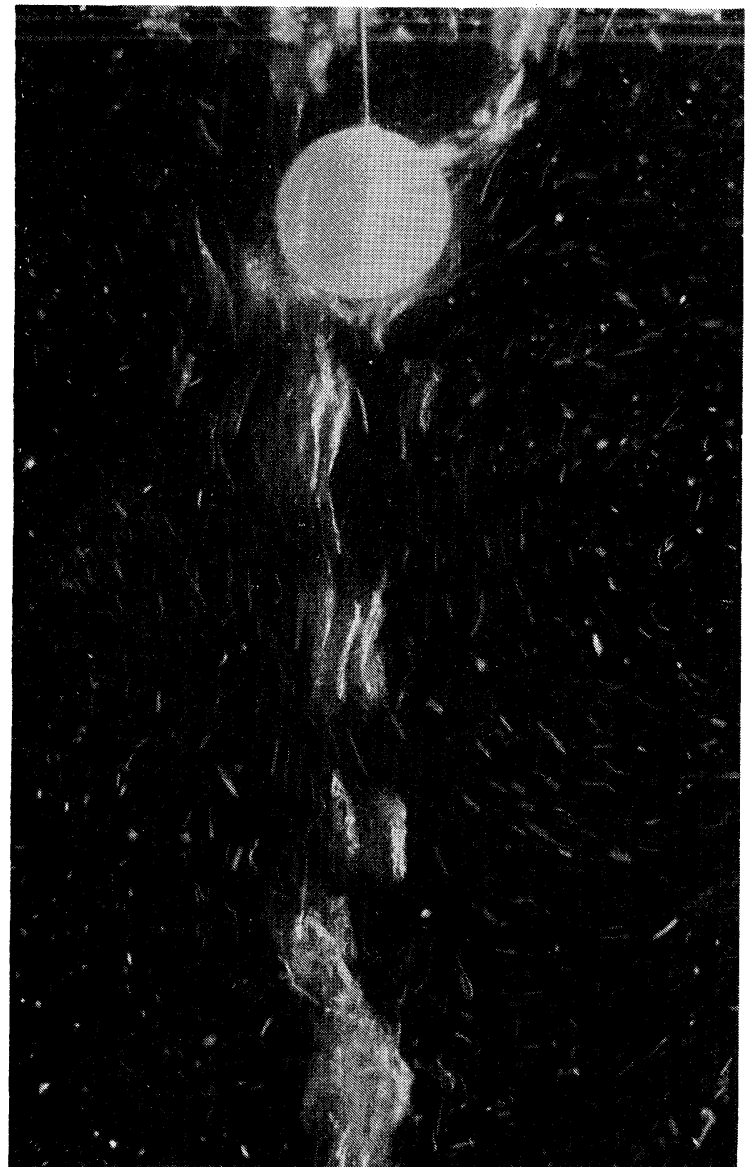

Photo. 2. Flow pattern established in the bath by the gas injection.

consumed at the orifice and $6 \%$ of it was transferred to the bath. Usually the value of this term is very small and hence neglected, but is not negligible when the bath temperature is high and the gas flow rate is large.

The kinetic energy per unit time of the upward flow which has a circular horizontal cross section with radius $r$ is

$$
W_{\mathrm{f}}=\frac{1}{2}\left(\pi r^{2} \rho_{1} v\right) v^{2}
$$

The value of $r$ was obtained from the photograph. Here, the volume of gas bubbles in the upward flow is neglected for simplicity, since it was observed to be small, though the evaluation of gas hold up in such a flow seems to be another important topic.

From the assumption:

$$
W_{\mathrm{f}}=W_{\mathrm{b}}+0.06 W_{\mathrm{g}}
$$

Then the flow velocity $v$ is obtained. Once the flow velocity $v$ is obtained, $R e$ which will be used later can be calculated by Eq. (6):

$$
R e=\frac{\rho_{1} v D}{\mu_{b}}
$$

Physical constants of water used in the present study are shown in Table 1.
Table 1. Physical constants of water used in the present study.

\begin{tabular}{c|ccccc}
\hline $\begin{array}{c}T_{b} \\
\left({ }^{\circ} \mathrm{C}\right)\end{array}$ & $\begin{array}{c}\mu_{b}{ }^{*} \\
(\mathrm{cp})\end{array}$ & $\begin{array}{c}\rho_{1} \\
\left(\mathrm{~g} / \mathrm{cm}^{3}\right)\end{array}$ & $\begin{array}{c}k \times 10^{3} * \\
\left(\mathrm{cal} / \mathrm{cm} \cdot \mathrm{s} \cdot{ }^{\circ} \mathrm{C}\right)\end{array}$ & $\begin{array}{c}C_{p}{ }^{*} \\
\left(\mathrm{cal} / \mathrm{g} \cdot{ }^{\circ} \mathrm{C}\right)\end{array}$ & $\begin{array}{c}P r \\
(-)\end{array}$ \\
\hline 0 & 1.827 & 1.020 & 1.338 & 1.005 & 13.73 \\
7.5 & 1.392 & 1.020 & 1.373 & 1.003 & 10.16 \\
15 & 1.144 & 1.019 & 1.406 & 1.000 & 8.137 \\
17 & 1.083 & 1.018 & 1.415 & 1.000 & 7.654 \\
20 & 1.022 & 1.018 & 1.427 & 0.9994 & 7.158
\end{tabular}

* Y.S. Touloukian et al.: Thermophysical Properties of Matter. The TPRG Data Series, Plenum, New York and Washington, (1970). $\operatorname{Pr}=\frac{G_{p} \mu_{b}}{k}$

\section{Results and Discussion}

\section{Procedure for Obtaining the Value of Heat Transfer Coefficient}

An example of the variation in the radius of the ice sphere with time is shown in Fig. 2 in which linear relationships can be recognized. The figure also shows that the melting rate increases with an increase in the gas flow rate.

The melting rate can be expressed by the following equation with an assumption that the heat transferred to the ice sphere is used for melting it only:

$$
-\frac{d R}{d t}=\frac{h}{\rho_{S} \Delta H}\left(T_{b}-T_{f}\right)
$$

The value of $h$ can be obtained from Eq. (7), since the experimental results give the melting rate, while other parameters are constant.

\section{Applicability of Heat Transfer Equations}

The heat transfer phenomenon between a sphere and a single phase fluid has often been studied and several numerical expressions for it are available. Metal spheres were usually used in previous studies $^{\mathbf{4}, 6,7)}$ and hence the applicability of a few equations shown in these studies to the ice spherewater system was preliminarily examined.

The results presented in Fig. 3 show that Eq. (8), by Whitaker, $\left.{ }^{4}\right)$ gives values very close to the experimental values, Eq. (9), by Vliet and Leppert, ${ }^{6)}$ gives slightly different values, while Eq. (10), which was presented by Ranz and Marshall ${ }^{8)}$ and had often been used, gives further different values:

$$
\begin{array}{r}
\mathcal{N} u-2=\left(0.4 \operatorname{Re}^{1 / 2}+0.06 \operatorname{Re}^{2 / 3}\right) \operatorname{Pr}^{0.4}\left(\mu_{b} / \mu_{0}\right)^{1 / 4} \\
\mathcal{N} u \operatorname{Pr}^{-0.3}\left(\mu_{0} / \mu_{b}\right)^{1 / 4}=1.2+0.53 \operatorname{Re}^{0.54} \ldots \ldots \ldots \ldots \\
\mathcal{N} u=2+0.6 \operatorname{Re}^{1 / 2} \operatorname{Pr}^{1 / 3} \ldots \ldots \ldots \ldots \ldots
\end{array}
$$

After the value of $\mathcal{N} u$ is obtained from one of these equations, heat transfer coefficient is calculated by Eq. (11):

$$
h=\frac{\mathcal{N} u k}{D}
$$

An example of such calculation is shown in Table 2. 


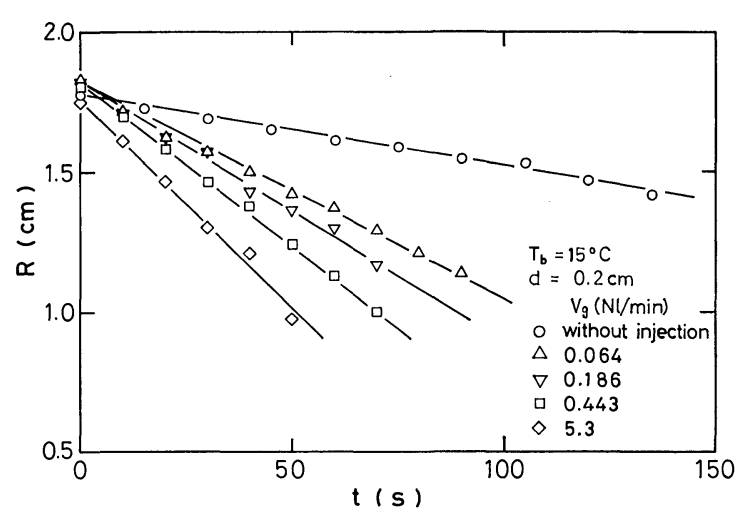

Fig. 2. Variation in the radius of the ice sphere with time.

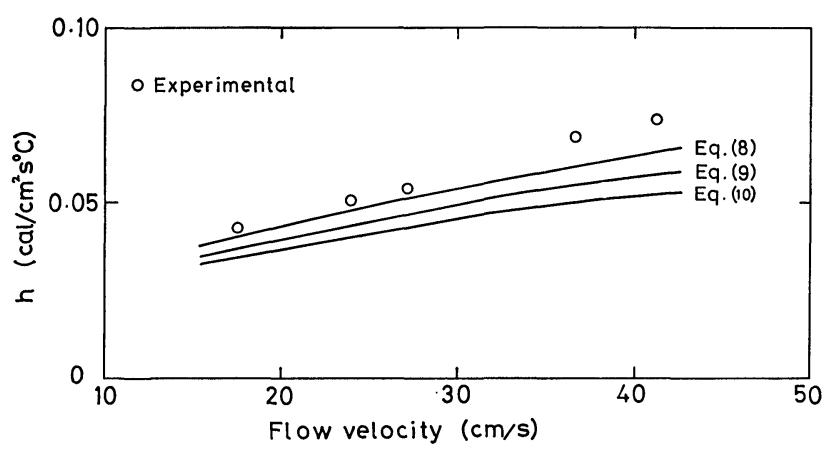

Fig. 3. Comparison of values of $h$ obtained by the preliminary experiment and the calculation with Eqs. (8) to $(10)$.

Table 2. An example of the calculation of $h$ by Eq. (8), (9), or (10).

\begin{tabular}{|c|c|c|c|c|}
\hline $\begin{array}{c}v \\
(\mathrm{~cm} / \mathrm{s})\end{array}$ & $\begin{array}{c}R e \\
(-)\end{array}$ & $\begin{array}{c}P r \\
(-)\end{array}$ & $\begin{array}{r}\mathcal{N} u \\
(-)\end{array}$ & $\begin{array}{c}h \\
\left(\mathrm{cal} / \mathrm{cm}^{2} \cdot \mathrm{s} \cdot{ }^{\circ} \mathrm{C}\right)\end{array}$ \\
\hline \multirow{3}{*}{24} & \multirow{3}{*}{6330} & \multirow{3}{*}{10.16} & 125.7 by Eq. (8) & 0.0479 \\
\hline & & & 114.3 by Eq. (9) & 0.0436 \\
\hline & & & 105.4 by Eq. (10) & 0.0402 \\
\hline
\end{tabular}

In Fig. 3 the experimental values for flow velocities of 36.7 and $41.3 \mathrm{~cm} / \mathrm{s}$ deviated from the curve for Eq. (8). The reason for this is not clear. However, as one possible explanation, this was considered to be due to the slight vibration of the specimen sphere. This vibration was inevitable because the specimen sphere was supported by a thin supporting rod and the degree of vibration increased as the flow velocity became large.

A comparison of the present experimental results with those obtained by other researchers is also shown in Fig. 4. The data of the other researchers were summarized by Whitaker. ${ }^{4}$ Vliet and Leppert ${ }^{6}$ ) obtained their results from the experiment on heat transfer between a copper sphere and water. Kramers used a steel sphere-air, water or oil system and Yuge used a brass or carbon-chrome steel sphere-air system.

The present results are in good accordance with other researchers' data and can be expressed by Eq. (8), hence Eq. (8) will be used for estimating the heat transfer coefficient under gas injection conditions later.
The Reynolds number is defined here by the initial diameter of the ice sphere.

\section{Influence of the Orifice Diameter}

The influence of the orifice diameter upon the value of $h$ is shown in Fig. 5 which was obtained for various orifice diameters and gas flow rates. This figure shows that the influence of the orifice diameter is very small and the gas flow rate has a larger influence.

This can be explained from the visual observation that the flow pattern of the upward flow did not vary much with the orifice diameter. This may be understood also from the following consideration on the average bubble diameter.

The size of the bubble in a liquid bath was reported $^{9-13)}$ to be dependent upon various parameters. Among several equations expressing the bubble size, Eq. (12) given by Davidson and Amick ${ }^{10}$ ) was found to be applicable under the present experimental conditions:

$$
\begin{aligned}
& d_{b}=0.54\left(V_{\mathrm{g}}^{\prime} d^{0.5}\right)^{0.289} \\
& 0.28<V_{\mathrm{g}}^{\prime} d^{0.5}<141
\end{aligned}
$$

The bubble diameter calculated by Eq. (12) showed that the influence of the orifice diameter is very small and the influence of the gas flow rate is much larger. It was also reported ${ }^{13)}$ that the gas hold up was independent of the orifice diameter.

\section{Infuence of the Vessel Shape}

The influence of the vessel shape will be discussed. The results obtained for various vessels are shown in Fig. 6. This figure shows that similar values of $h$ are obtained, except for the case of vessel (b) with the highest gas flow rate.

This can be explained from the observation that the flow pattern of the upward flow does not change much with the vessel shape under the present experimental conditions. However, in the case of vessel (b) with the highest gas flow rate, the flow pattern was influenced by the side walls with a short distance apart and thus the upward flow was no longer cylindrical. This may be the reason for the highest value of $h$ obtained.

\section{Influence of the Gas Flow Rate}

From the discussions of the previous sections it may be said that the gas flow rate is most influencial of the three parameters.

The influence of the gas flow rate can be seen, for example, in Fig. 7, in which solid line shows the calculated values by Eq. (8) with the upward flow velocity obtained by method (2). The average velocity of the upward flow increased as the gas flow rate increased. The calculated values are in reasonable agreement with the experimental values, though influences of the gas volume in the upward flow and the turbulence around the ice sphere due to the gas bubbles were neglected.

Further, the comparison of methods (1) and (2) 


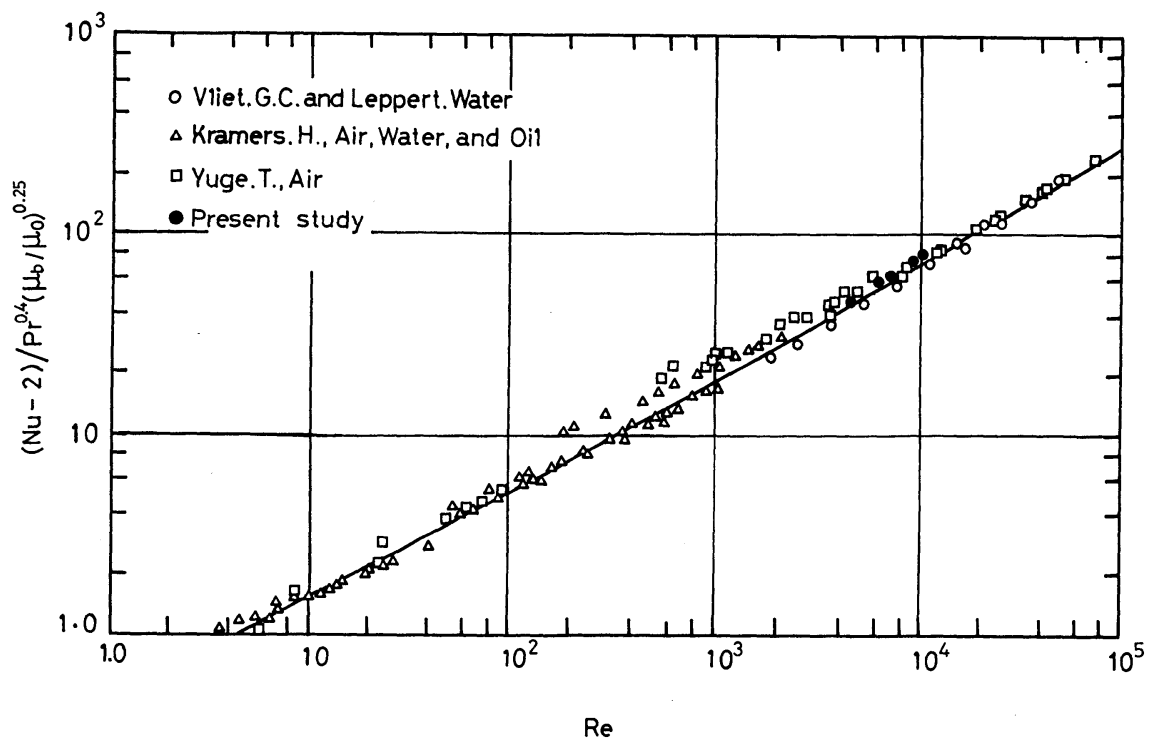

Fig. 4. Comparison of Nusselt numbers obtained by the preliminary experiment and by other researchers. The solid line was obtained from Eq. (8):

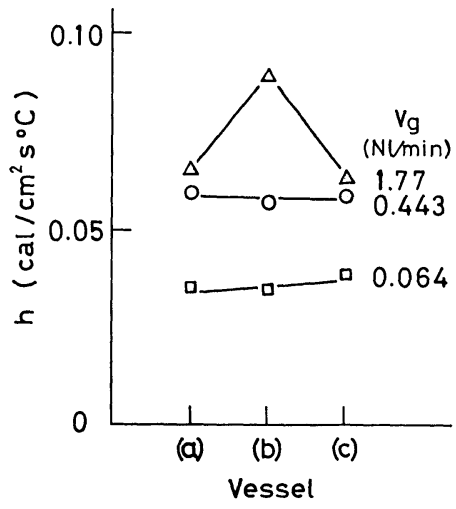

Orifice diameter is $0.1 \mathrm{~cm}$.

$T_{b}$ is $17^{\circ} \mathrm{C}$ for Vessel (a).

$T_{b}$ is $20^{\circ} \mathrm{C}$ for Vessels (b) and (c).

Fig. 6. Variation of heat transfer coefficient $h$ with the vessel shape and gas flow rate.

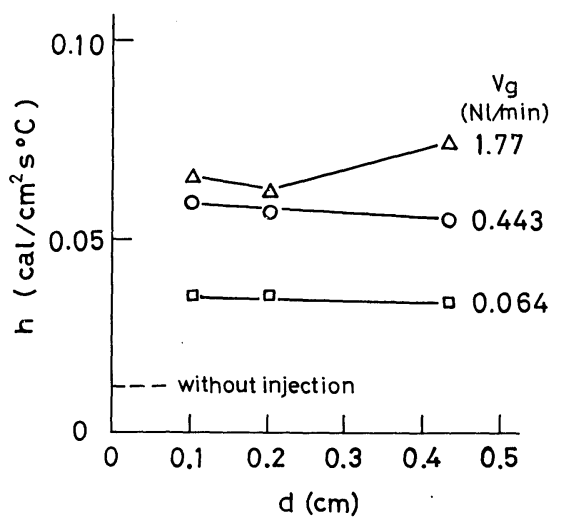

Vessel (a)

$T_{b}$ is $17^{\circ} \mathrm{C}$ for $d=0.1$ and $0.43 \mathrm{~cm}$. $T_{b}$ is $15^{\circ} \mathrm{C}$ for $d=0.2 \mathrm{~cm}$.

Fig. 5. Variation of heat transfer coefficient $h$ with the orifice diameter and gas flow rate.

with the experimental results is shown in Fig. 8. They are again in reasonable agreement. Therefore, it is possible to predict the value of $h$ when the average velocity of the upward flow is known.

The comparison of Figs. 3 and 7 indicates that the effect of gas injection at rates from 0.064 to $5.3 \mathrm{~N} l / \mathrm{min}$ is almost equivalent to the effect due to the water flow at rates from about 10 to about $50 \mathrm{~cm} / \mathrm{s}$, because the values of $h$ are very close each other.

\section{Summary}

The melting rate of an ice sphere placed in the upward flow in a water bath generated by the gas injection at the bath bottom increased with an increase in the gas flow rate. This is due to the fact that the average velocity of the upward flow increases as the gas flow rate increases.

The orifice diameter and vessel shape have little effect upon the melting rate as long as the flow pattern of the upward flow is not influenced by the vessel walls.

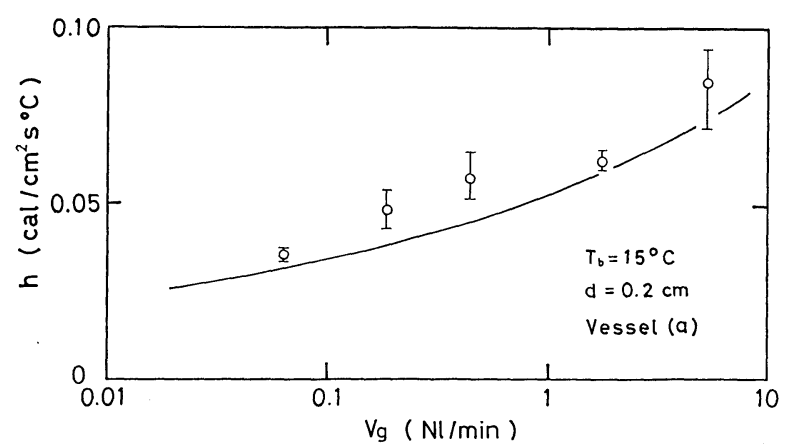

Fig. 7. Variation of heat transfer coefficient $h$ with the gas flow rate and comparison of experimental and calculated values of $h$. The solid line shows the values calculated by Eq. (8).

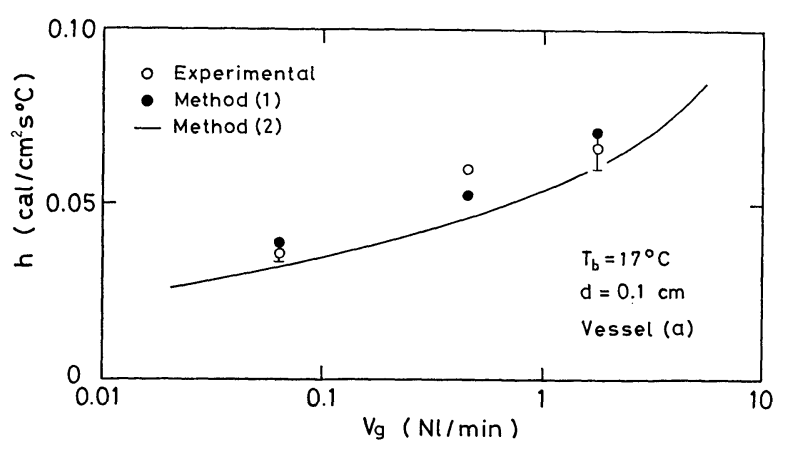

Fig. 8. Comparison of experimental and calculated values of $h$ under gas injection conditions.

It was found that Whitaker's heat transfer equation was applicable to estimate the heat transfer coefficient when the average velocity of the upward flow is known.

An energy balance consideration was also presented to evaluate the average velocity of the upward flow.

\section{Nomenclature}

$C_{p}:$ specific heat of water $\left(\operatorname{cal} / \mathrm{g} \cdot{ }^{\circ} \mathrm{C}\right)$

$d$ : orifice diameter $(\mathrm{cm})$ 
$d_{\mathrm{b}}$ : bubble diameter $(\mathrm{cm})$

$D$ : initial diameter of ice sphere $(\mathrm{cm})$

$g$ : gravitational acceleration $\left(\mathrm{cm} / \mathrm{s}^{2}\right)$

$h$ : heat transfer coefficient $\left(\mathrm{cal} / \mathrm{cm}^{2} \cdot \mathrm{s} \cdot{ }^{\circ} \mathrm{G}\right)$

$H$ : depth of water bath (cm)

$\Delta H$ : latent heat of fusion (cal $/ \mathrm{g}$ )

$k$ : thermal conductivity of water $\left(\mathrm{cal} / \mathrm{cm} \cdot \mathrm{s} \cdot{ }^{\circ} \mathrm{C}\right)$

$M$ : molecular weight of gas $(\mathrm{g} / \mathrm{mol})$

$\mathcal{N} u$ : Nusselt number (-)

$P_{\mathrm{a}}$ : atmospheric pressure $\left(\mathrm{dyn} / \mathrm{cm}^{2}\right)$

Pr: Prandtl number (-)

$r$ : radius of upward flow $(\mathrm{cm})$

$R$ : radius of ice sphere $(\mathrm{cm})$, gas constant (erg/ $\mathrm{K} \cdot \mathrm{mol}$ )

Re: Reynolds number (-)

$S:$ orifice area $\left(\mathrm{cm}^{2}\right)$

$t:$ time (s)

$T$ : absolute temperature $(\mathrm{K})$

$\mathcal{T}_{b}$ : temperature of bulk water $\left({ }^{\circ} \mathrm{G}\right)$

$\mathcal{T}_{f}$ : temperature of water at ice sphere surface $\left({ }^{\circ} \mathrm{C}\right)$

$u$ : gas velocity at orifice $(\mathrm{cm} / \mathrm{s})$

$v$ : velocity of upward flow $(\mathrm{cm} / \mathrm{s})$ velocity of water flow $(\mathrm{cm} / \mathrm{s})$

$V_{\mathrm{g}}$ : gas flow rate $(\mathrm{N} l / \mathrm{min})$

$V_{\mathrm{g}}^{\prime}:$ gas flow rate $\left(\mathrm{cm}^{3} / \mathrm{s}\right)$

$W_{\mathrm{b}}$ : work per unit time due to buoyancy ( $\left.\mathrm{erg} / \mathrm{s}\right)$

$W_{\mathrm{g}}$ : kinetic energy per unit time of injected gas at orifice $(\mathrm{erg} / \mathrm{s})$

$W_{\mathrm{f}}$ : kinetic energy per unit time of upward flow (erg/s)

$\mu_{b}: \quad$ viscosity of bulk water (cp)

$\mu_{0}$ : viscosity of water at ice sphere surface (cp) $\rho_{\mathrm{g}}:$ density of gas $\left(\mathrm{g} / \mathrm{cm}^{3}\right)$

$\rho_{1}$ : density of water $\left(\mathrm{g} / \mathrm{cm}^{3}\right)$

$\rho_{\mathrm{s}}$ : density of ice $\left(\mathrm{g} / \mathrm{cm}^{3}\right)$

\section{Acknowledgements}

The authors are grateful to Professor I. Tanaka and Associate Professor T. Suzuki of the Department of Naval Architecture, Osaka University for their providing the opportunity to use the circulating water channel.

\section{REFERENGES}

1) K. Nakanishi and K. Sanbongi: Tetsu-to-Hagané, 65 (1979), 138.

2) Y. Sawamura: Tetsu-to-Hagané, 63 (1977), 1953.

3) L. H. Lehrer: I \& EC Process Design and Development, 7 (1968), 226.

4) S. Whitaker: AIChEJ, 18 (1972), 361.

5) K. Mori and M. Sano: Tetsu-to-Hagané, 67 (1981), 672.

6) G. C. Vliet and G. Leppert: J. Heat Transfer, Trans. ASME, Ser. $C, 83$ (1961), 163.

7) T. Yuge: J. Heat Transfer, Trans. ASME, Ser. C, 82 (1960), 214.

8) W. E. Ranz and W. R. Marshall: Chem. Eng. Prog., 48 (1952), $141 \& 173$.

9) D. W. van Krevelen and P. J. Hoftijzer: Chem. Eng. Prog., 46 (1950), 29.

10) L. Davidson and E. H. Amick: AIChEJ, 2 (1956), 337.

11) T. Tadaki and S. Maeda: Kagaku Kogaku (Chem. Eng. Japan), 27 (1963), 147.

12) F. Yoshida and K. Akita: AIChEJ, 11 (1965), 9.

13) M. Sano and K. Mori: Tetsu-to-Hagané, 60 (1974), 348. 